\title{
Properly planned de-institutionalisation for mental illness maintained most in community living with enhanced quality of life
}

Newton L, Rosen A, Tennant C, et al. Deinstitutionalisation for long-term mental illness: an ethnographic study. Aust N ZJ Psychiatry 2000 Jun;34:484-90.

QUESTION: What effects does de-institutionalisation have on the lives of residents who were admitted to hospital because of long term mental illness?

Design

Ethnography.

\section{Setting}

Northern Sydney Area Health Service, Australia.

\section{Patients}

47 hospital residents (hospitalised from 2-43 y) transferred to the community to stay in residential facilities in middle to upper class areas.

\section{Methods}

Data were collected using participant observational fieldwork, open ended and semistructured interviews, life history taking and perusal of written records. Fieldwork occurred on a daily basis over a 2.5 year period, approximately 8 months before hospital discharge and then 2 years after discharge. Data collection comprised daily field note taking, audiotaped interviews, and summaries of case records. Ethnographic themes were generated from observations occurring during the study.

\section{Main findings}

Initially residents had to acquire new functional living skills and develop socially appropriate behaviours, which were not easy tasks. There was no sudden deterioration in the first few weeks after discharge. Community staff however, had expected the residents to progress at a faster rate. 40 of the 47 residents developed the skills necessary to maintain the transition to community living.

Between 3 and 9 months after discharge, some social behaviour deteriorated. The initial delight and enthusiasm immediately after hospital discharge waned. Exacerbation of symptoms along with aggressive and violent behaviour from some of the residents unsettled others in the community facilities. Residents were encouraged to be more actively involved in the community, which created stress, and many queried their own ability to cope. Residents who returned to hospital for long term care (5 of the 7) did so during this period. Social behaviour improved by the second year of follow up. This was the first time a substantive improvement was seen in depressive affect. Residents seemed more relaxed and were accepted by others within the community and mental health programmes.

40 participants who continued to live outside the hospital reported a preference for community living. Particularly, the importance of freedom, having some choice and control over their future, and the dignity afforded to them as everyday citizens in mainstream society were valued greatly by the residents.

\section{Conclusion}

In residents admitted to hospital because of long term mental illness, a properly planned process of deinstitutionalisation maintained most in the community with a self reported enhanced quality of life.

\section{COMMENTARY}

The findings presented by Newton $e t a l$ are consistent with other studies that have found that it takes several months, or even years after hospital discharge, before clients with long term mental illness feel settled into their community and establish new relationships, and that assistance is needed with this transition. ${ }^{1-3}$

The longitudinal nature of this study over 2.5 years permitted observation of change over time as residents adjusted to de-institutionalisation. This lengthy period for data collection allowed for an indepth exploration of issues The identification of phases within the deinstitutionalisation process has clear practice implications for nurses.

The initial period after discharge has traditionally been seen as a period requiring additional support. The residents in this study had adequate support during the initial period, probably in part because of this conventional wisdom. After the "honeymoon" phase, however, participants entered a period where stress and instability became a challenge for some. Interestingly, this occurred around 6 months after discharge. This is often a time when the initial after discharge support may be reduced. The results imply that discharge planning needs to go beyond the immediate discharge period, and that the provision of enhanced support may need to be available for a longer period. It would have been useful to have more information about the 7 participants who did not remain in the community. Were there any commonalities or identified unmet needs?

Staff in this study lamented the slow progress of residents in the community to acquire new skills and to become less dependent. Programmes and staff assisting clients to make this transition need to allow for adequate time for skill acquisition and set realistic time frames for goals.

Despite the long process, the individuals as a whole appreciated the opportunity of community living. They most valued their freedom. Not surprisingly, the bottom line for the study participants was that they prefer to live out of hospital.

Cheryl Forchuk, RN, PhD Associate Professor/Nurse Scientist University of Western Ontario/ London Health Sciences Centre London, Ontario, Canada

1 Baronet AM, Gerber GJ. Psychiatric rehabilitation: efficacy of four models. Clin Psychol Rev 1998;18:189-228.

2 Forchuk C. The orientation phase of the nurse-client relationship: how long does it take? Perspect Psychiatr Care 1992;28:7-10.

3 Appleby L, Conklin C, Williamson P. Transitional programming. Hosp Community Psychiatry 1990;41:680-1.
Sources of funding: Australian Commonwealth Department of Family and Community Services-Research and Development Advisory Committee and the Northern Sydney Area Health Services.

For correspondence: Professor C Tennant, Department of Psychological Medicine, University of Sydney, Royal North Shore Hospital, Block 4, Level 5, St Leonards, New South Wales 2065, Australia.Fax +612 99267730. 